\title{
Recreação e vida ao ar livre em parques infantis de São Paulo na coleção de desenhos de Mário de Andrade
}

\author{
[ Recreation and outdoor life in São Paulo's playgrounds \\ in Mário de Andrade's collection of drawings
}

\section{Ingrid Dittrich Wiggers ${ }^{\mathrm{I}}$}

\section{Carmen Lucia Soares ${ }^{2}$}

Nossa pesquisa, realizada em 20I4-20I7, foi beneficiada pela experiência e dedicação de Bianca Dettino, Elisabete Ribas, Maria Itália Causin e suas respectivas equipes do IEB/USP. Agradecemos também ao CNPq.

\begin{abstract}
RESUMO-O Projeto Parques Infantis, implantado na década de I930, propôs a criação de instituições que configurassem a fusão entre o movimento pedagógico renovador e a estética modernista. Entre as atividades desenvolvidas pelas crianças estão os desenhos, que compõem uma coleção formada por Mário de Andrade. O artigo examina os itens desse acervo, tomando-os como fontes e debruçando-se sobre aqueles que representam brincadeiras e jogos. Foram ilustradas brincadeiras tradicionais, equipamentos dos parques, jogos esportivos e manifestações folclóricas. Ressalte-se, ainda, a presença da natureza na composição dos desenhos, bem como traços de um desenvolvimento tecnológico. -PALAVRAS-CHAVE • Desenho infantil; parques infantis; brincadeiras; natureza; São Paulo.
\end{abstract}

Recebido em I2 de dezembro de 2018

Aprovado em I8 de novembro de 2019

\begin{abstract}
- ABSTRACT - Implemented in the I930s, São Paulo's playgrounds were institutions that illustrated the fusion of the education renovation movement and the aesthetics of modernist. Drawings are among the activities developed by the children, and make up a collection assembled by Mário de Andrade. This article examines this collection, considering the drawings sources and looking into those that represent play and games. Children drew children's traditional play, the park's equipment, sports games and folkloric manifestations. In the composition of the drawings, the presence of nature is also noteworthy, and so are traces of a technological development. · KEYWORDS - Children's drawing; playground; play; nature; Sao Paulo.
\end{abstract}

WIGGERS, Ingrid Dittrich; SOARES, Carmen Lucia. Recreação e vida ao ar livre em parques infantis de São Paulo na coleção de desenhos de Mário de Andrade. Revista do Instituto de Estudos Brasileiros, Brasil, n. 74, p. 302-322, dez. 2019.

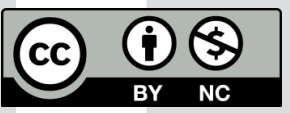

DOI: http://dx.doi.org/10.11606/issn.2316-901X.v0i74p302-322

I Universidade de Brasília (UnB, Brasília, DF, Brasil).

2 Universidade Estadual de Campinas (Unicamp, Campinas, SP, Brasil). 


\section{A COLEÇÃo DE DESENHOS INFANTIS}

Na década de I930, foram implantados em São Paulo os chamados parques infantis, criação do Departamento de Cultura e Recreação, sob a direção de Mário de Andrade. Essas instituições estavam articuladas a um projeto político, cultural e educacional mais abrangente, representando iniciativa de destaque no âmbito tanto de uma nova visão urbanística como do movimento pedagógico renovador. Os parques repercutiram na construção de uma pedagogia da educação infantil, mas, sobretudo, se tornaram verdadeiros territórios da meninada paulista. De acordo com Fonseca (I98I; I985) e Faria (I999a; I999b), esses parques foram edificados como alternativa às pré-escolas e aos espaços filantrópicos, e, para além disso, Mário de Andrade fez deles palco da produção artística infantil por acreditar na criança como portadora de cultura. Também Dias (20I7) evidenciou que o interesse na infância gerou uma tendência importante na literatura modernista, marcada por imagens contraditórias, que oscilaram entre o rural e o urbano, entre a tradição e a vanguarda. Como observou Gobbi (2006, p. I76), "Mário de Andrade representará no modernismo brasileiro o papel do artista que encontra nas crianças alguns de seus interlocutores, capazes de despertar sua curiosidade através das próprias criações”.

Esses espaços, portanto, serviam ao atendimento dos filhos de famílias das classes populares, que lá recebiam assistência médica e alimentação e ao mesmo tempo desenvolviam atividades voltadas à arte, consolidando um projeto de educação integral. As atividades artísticas presentes foram amplamente registradas por meio de fotografias de autoria de Benedito Junqueira Duarte 3 no período de implantação dos parques (BRITO, 20I6). Ao ar livre, as crianças foram captadas ao redor de mesas, sentadas em pequenas cadeiras, desenhando; muitas vezes se encontram sem camisa, desfrutando, assim, de sensação de "liberdade corporal", em geral por elas tão apreciada (Acervo Fotográfico do Museu da Cidade de São Paulo, Tombo DC/0000237/A).

Entre as atividades realizadas pelas crianças estão os desenhos, expressão gráfica

3 As fotografias de Benedito Junqueira Duarte encontram-se disponíveis para consulta on-line no Acervo Fotográfico do Museu da Cidade de São Paulo. 
que, naquelas instituições, ocupou lugar de destaque, conforme atesta a realização de um concurso promovido pelo Departamento de Cultura e Recreação de São Paulo. Naquele evento, cada criança poderia escolher o que desenhar, bem como a forma de fazê-lo4. No verso das folhas as instrutoras escreveram: "Foi respeitada a expressão da criança quando disse o que fez", sugerindo espontaneidade da produção gráfica 5 . Os desenhos que fizeram parte do referido concurso compõem o acervo disponível na Coleção de Artes Visuais do Instituto de Estudos Brasileiros da Universidade de São Paulo (IEB/USP) e constituem as fontes deste artigo. O acervo é composto de 2.I6o obras, sendo a maior parte identificada pelo nome do autor, idade, instituição de origem, nacionalidade dos pais e "cor". Os trabalhos que participaram do concurso foram produzidos tanto nos parques infantis como também na Biblioteca Infantil, outra divisão daquele departamento. $\mathrm{O}$ acervo ainda guarda uma pequena parcela produzida em escolas e outra, ainda menor, produzida por filhos de amigos de Mário de Andrade. Trata-se da única coleção de desenhos infantis conhecida no Brasil aberta à consulta de pesquisadores, o que sugere sua importância como fonte para estudo da história da infância brasileira ${ }^{6}$.

Mário de Andrade de fato se interessou pelos desenhos infantis, inaugurando historicamente a valorização do tema entre intelectuais brasileiros (AMIN; REILY, 2008). Isso pode ser constatado em sua biblioteca, que reúne oito livros sobre o assunto, incluindo obras clássicas 7 , bem como manuscritos ${ }^{8}$ e numerosas anotações para o Curso de Filosofia e História da Arte, ministrado na Universidade do Distrito Federal, em I938 (Arquivo IEB/USP, Fundo Mário de Andrade, MA-MMA-037-0090 a

4 As bases do concurso foram redigidas pelo próprio Mário de Andrade (Coleção de Artes Visuais do IEB/USP, Fundo Mário de Andrade, MA-DI-2258).

5 Apesar desses registros, Brito (20I6) problematiza esse aspecto da produção gráfica das crianças, sugerindo influência das instrutoras.

6 Em I988, pela primeira vez, a coleção foi objeto de exposição do Museu de Arte Contemporânea da USP, sob a coordenação de Ana Mae Barbosa. Em 2005, outra exposição de caráter interativo foi organizada no Serviço Social do Comércio (Sesc - Pinheiros), também em São Paulo, dessa vez coordenada por Marcia Gobbi.

7 Entre as obras destaca-se um exemplar do original em francês, Le dessin enfantin, de Georges Henri Luquet, publicado em I927, uma referência para os estudos do desenho infantil.

8 Um exemplo é o "Estudo sobre o desenho infantil entre as crianças de São Paulo sob o ponto de vista da beleza” (Arquivo IEB/USP, Fundo Mário de Andrade, MA-MMA-037-500 a 547). 
MA-MMA-037-I498). Há também muitas correspondências9, trocadas entre Mário e outros intelectuais, além de diversos artigos por ele publicados em jornais da época ${ }^{\mathrm{To}}$.

Estudos anteriores já exploraram a história dos parques infantis de São Paulo ${ }^{\text {Ir }}$. Contudo, apenas dois se detiveram especificamente sobre a coleção. De caráter pioneiro, a tese de Coutinho (2002) realizou exaustiva catalogação informatizada desse acervo, a fim de apoiar uma análise iconográfica, situando Mário de Andrade na gênese do estudo dos desenhos infantis. A autora buscou reconstruir e reinterpretar as intenções dele ao colecionar essas obras. Assim, os parques são destacados pela arte-educadora como instituições privilegiadas, onde se configurava a fusão entre o movimento pedagógico renovador, que concebia os espaços extraescolares de educar, e a estética dos projetos modernistas.

Posteriormente, Gobbi (20II) destacou que cada desenho dessa coleção da década de I930 era considerado por Mário de Andrade como resultado de soluções estéticas das crianças, o que as aproximava do campo das artes. Desse modo, o modernista convocou os referenciais da arte como bases para o estudo do desenho infantil, pois para ele esse tipo de produção típica das crianças seria provido de sensibilidade estética. O autor compôs uma etnografia dos desenhos e procurou "conhecer e revelar os assuntos, os traçados, as formas e outros elementos ao descrever, dialogar e levantar dados diversos sobre os desenhos em si, associando a isso a data de criação, o sexo, a idade, a nacionalidade dos pais de quem os criou" (GOBBI, 2006, p. I78).

Os desenhos infantis não são espécie de fonte comumente utilizada na pesquisa em história. Meda (2007; 20I4) apresenta razões culturais e materiais para a sua ausência na historiografia. Entre elas se destacam a dificuldade de interpretação, por sua natureza icônica, o fato de serem um produto da expressão de crianças, sujeitos tradicionalmente considerados passivos para a história e, por fim, a escassez desse tipo de material em arquivos e museus, que, geralmente, não é guardado por muito tempo.

Todavia, os desenhos infantis possuem uma heurística particular quando se leva em conta uma orientação metodológica adequada para a sua apreciação e

9 Algumas correspondências foram trocadas com Nicanor Miranda, diretor da Divisão de Educação e Recreio do Departamento de Cultura e Recreação. Em data anterior a novembro de I937 se abordam relações entre a motricidade e o desenho (Arquivo IEB/USP, Fundo Mário de Andrade, MA-C-CPMVA5I5I). Outra carta, de 4 de dezembro de 1937, foi enviada por Lenyra Camargo Fraccaroli, diretora da Biblioteca Infantil, sugerindo a realização de uma exposição pública dos desenhos (Coleção de Artes Visuais IEB/USP, Fundo Mário de Andrade MA-DI-I684). Outras de cordialidade também foram encontradas, do mesmo remetente, como, por exemplo, de I4 de julho de I938, em agradecimento pelo apoio à premiação do concurso de desenho infantil (Arquivo IEB/USP, Fundo Mário de Andrade MA-C-CPL5978). Uma curiosidade é que essa última contém mensagens das próprias crianças premiadas.

Io Artigo intitulado "Pintura infantil" foi publicado no Diário Nacional, em 23 de novembro de I930 (ANDRADE, I930).

II Um conjunto de 25 trabalhos foi localizado - incluindo monografias, dissertações e teses produzidas no período compreendido entre I978 e 2016 -, por meio de busca sistemática feita a partir da palavra-chave "parques infantis", nos catálogos das bibliotecas da USP e da Universidade Estadual de Campinas (Unicamp) (FERREIRA; WIGGERS, 20I9). 
interpretação histórica. Durante cinco missões científicas ao IEB/USP, nos anos de 20I4, 20I5, 2016 e 20I7, cada uma delas com cerca de duas semanas de duração, sob o acompanhamento de arquivistas e bibliotecários dessa importante instituição dedicada à memória da cultura brasileira, apreciamos detalhadamente a coleção completa. Examinamos cada uma das I7 caixas guardadas na Coleção de Artes Visuais. Folheamos os 2.I60 originais um a um, tendo como base o inventário da "Série: Desenhos Infantis", coordenado pela profa. dra. Telê Ancona Lopez, a partir de I984 $4^{\text {I2 }}$. Boa parte da coleção está identificada com informações de que, segundo Meda (20I4), precisamos dispor para interpretar adequadamente a história nela contada, como idade, orientações recebidas, nível de espontaneidade, data e local. Os trabalhos foram descritos considerando, inicialmente, temas representados, buscando-se observar especificamente as brincadeiras e jogos realizados ao ar livre. Essa escolha se justifica na identificação dos parques infantis como espaços projetados para recreação e divertimentos.

Foram examinados também documentos, imagens e livros do Fundo Mário de Andrade, além de outros correlatos, como o Fundo Fernando de Azevedo, a fim de suprir informações relativas ao contexto histórico e cultural em que se insere a coleção. Desse modo, a pesquisa combinou fontes localizadas nos principais setores do IEB, abrangendo a Coleção de Artes Visuais, o Arquivo, bem como a Biblioteca. Complementarmente, conforme recomenda Gobbi (2012) para uma adequada interpretação iconográfica, exploramos fotografias dos parques, da década de I930, disponíveis no acervo do Museu da Cidade de São Paulo ${ }^{\mathrm{T3}}$, produzindo um diálogo entre elas e os desenhos. Esse conjunto de vestígios favoreceu uma perspectiva da história cultural, observando-se indissociabilidade entre representações e práticas (CHARTIER, 2002; CERTEAU, 20I4). Esse tratamento teórico-metodológico visa apoiar o caráter introdutório e ao mesmo tempo desafiador da pesquisa, levando em conta o esforço de realizar uma interpretação dos desenhos infantis de forma articulada ao projeto dos parques.

Abordamos a seguir a proposta pedagógica do Projeto Parques Infantis. Esta valorizou a natureza e seus elementos, bem como uma educação do corpo ao ar livre. Por outro lado, ressalvamos também sua dimensão de controle social da infância paulista. Destacamos, ainda, brincadeiras e jogos ilustrados pelas crianças em seus desenhos e, por fim, realçamos outros elementos que se destacaram na coleção, como as referências à natureza e seus elementos, além do desenvolvimento tecnológico, enquanto partes de um mesmo contexto.

I2 O inventário “Série: Desenhos Infantis” é constituído de um rol de 2.262 desenhos e documentos que compõem a coleção, incluindo número, autor e tema, sendo formado por 86 páginas. De acordo com a profa. dra. Telê Ancona Lopez, foi mantida a mesma ordenação dos desenhos, tal como havia sido disposta por Mário de Andrade, seguindo orientações atuais da arquivologia. Para compreender detalhes desse inventário, entrevistamos também a pesquisadora Maria Izilda C. Nascimento, que colaborou diretamente na elaboração do mesmo.

I3 Uma seleção dessas fotografias foi publicada em formato de um álbum, pelo Departamento de Recreação e Cultura, em I937. Além das fotografias, contém belas ilustrações de Anita Malfatti e está disponível no acervo do IEB/USP, merecendo estudo detalhado empreendido por Silva (2008). 


\section{Parques infantis de São Paulo: ilhas de natureza}

O processo de implantação dos parques infantis na cidade de São Paulo teve início na gestão do prefeito Luiz Ignácio Romeiro de Anhaia Melloㄴ, com a inauguração em 23 de dezembro de I930 do então denominado "play-ground" como uma área reservada no interior do Parque D. Pedro II (INAUGURA-SE..., I930). Esse foi um reflexo de uma tendência de alcance internacional, orientada pelo playground movement, que teve início nos Estados Unidos da América em fins do século XIX. Trata-se de uma política de integração e assistência à infância no novo ambiente urbano que se formava naquela época, ao mesmo tempo que se intensificava o processo de industrialização (MERO, I908; MIRANDA, I94I; CAVALLO, I98I). No Brasil, essas ideias encontraram terreno fértil no Rio de Janeiro, logo no início do século XX, por meio da ação de instituições como a Associação Cristã de Moços (ACM), Rotary Club e Associação Brasileira de Educação (ABE), propagando-se gradativamente para outras regiões (FEIX, 2003; LINHALES, 2009; SILVA, 2009).

Em São Paulo, foi na gestão de Mário de Andrade no Departamento de Cultura e Recreação, ou seja, entre I935 e I938, que se observou um impulso dessa política, favorecendo a implantação de mais três parques localizados em bairros povoados por famílias de operários e imigrantes: do Ipiranga, da Lapa e de Santo Amaro. Deu-se, assim, elevada atenção aos parques infantis no cenário urbano emergente de São Paulo, integrados a um projeto político de alcance mais amplo.

O planejamento do Parque Infantil do Ipiranga foi delineado por Fernando de Azevedo, à época professor de sociologia no curso de aperfeiçoamento da antiga Escola Normal, depois Instituto Pedagógico Caetano de Campos (PENNA, 20Io), e que também coordenou a comissão designada para produzir um documento publicado sob o título "Praças de jogos para crianças: ensaio de hygiene social" (AZEVEDO, I930)5. O trabalho dessa comissão, além de contemplar as bases filosóficas e educacionais dos parques infantis, também apresenta detalhadamente as soluções urbanísticas, paisagísticas, arquitetônicas, bem como os equipamentos, atividades pedagógicas e seus respectivos objetivos, enfim um programa completo para orientar a sua implantação e funcionamento. Nesse sentido, Filizzola (2002) destacou a liderança de Fernando de Azevedo no projeto original dos parques, consolidando essa iniciativa como parte do movimento de renovação educacional das décadas de I920 e I930, no Brasil.

No bairro do Ipiranga o terreno disponível para a construção do parque era um

I4 Anhaia Mello foi um pioneiro da divulgação e promoção das novas tendências urbanísticas do período e, embora tenha sido prefeito de São Paulo por um curto intervalo, atuou desde cedo na implementação dos parques infantis. Em 1929, publicou um texto em que disse: "O conceito de parque evoluiu. [...] Eles agora destinam-se ao recreio ativo de todas as classes da população e de todas as idades, desde a criança na idade pré-escolar até o adulto. $\mathrm{O}$ tapete de relva transformou-se no play-ground, no play-field; o lago, na piscina ou no skatinpoun [sic]" (MELLO, I929).

I5 Segundo a publicação de I930, trata-se do resultado do trabalho de uma comissão constituída pela municipalidade de São Paulo, incluindo o próprio Fernando de Azevedo, Mário Cardim e Domício Pacheco e Silva. Esse texto foi publicado, posteriormente, em I960, como parte da terceira edição do livro intitulado $D a$ educação física: o que ela é, o que tem sido e o que deveria ser, compondo os apêndices dessa obra. 
quadrado de I0O x I0o m, a ser equipado com um edifício central contendo um pátio de duchas, salas de administração e de espera, varanda e pérgula; outro pequeno edifício lateral, com sala de ginástica e depósitos; tanque de vadear de $20 \mathrm{~m}$ de diâmetro de água corrente, para brincadeiras; três abrigos junto ao tanque de vadear; dois campos para jogos, sendo um de relva e outro de areia; quatro grandes pátios de areia batida para suportar balanços, cordas de nós, escadas de cordas, carrossel, escorregadores, escada horizontal, paralelas e gangorras, sendo que um desses deveria conter caixas de areia e brinquedos de dimensões adequadas a crianças menores (AZEVEDO, I930).

O padrão das plantas arquitetônicas dos parques infantis em seu período inicial previa uma área coberta discreta, ocupando em torno de I5\% do terreno, de acordo com a planta baixa desenhada por José Wasth Rodrigues (AZEVEDO, I930). A maior parte seria de espaço livre para a instalação de extenso gramado e generoso playground, envolvendo a meninada num amplo ambiente "natural"ז6.

Para além desse detalhamento arquitetônico e de indicação de atividades, "o plantio de árvores e arbustos em linha junto às cercas divisórias buscava amenizar o calor do verão e caracterizava espacialmente a praça" (NIEMEYER, 2005, p. I2). Os parques infantis, portanto, viriam a se caracterizar como verdadeiras "ilhas de natureza" cercadas pela cidade por todos os lados,

Pois, á medida que o surto maravilhoso da industria vae determinando o congestionamento dos bairros, os campos, os bosques e os riachos afastam-se do alcance das crianças, a que a valorisação crescente dos terrenos concorre para subtrahir o espaço, cada vez mais reduzido de pateos e dos pittorescos quintaes de arvores frondosas e carregadas de anos. (AZEVEDO, I930, p. 59-60).

A representação da natureza nos parques foi igualmente exaltada por Nicanor Miranda, o primeiro diretor da Divisão de Educação e de Recreios do Departamento de Cultura e Recreação.

A cidade vê-se assim, quer queira quer não, obrigada a resolver o problema da recreação e da juventude. As crianças e os adolescentes não devem ficar privados de suas necessidades biológicas. Sol, ar livre, companheiros, logradouros, apropriados para jogar, são elementos imprescindíveis à vida juvenil. Os Parques Infantis oferecemlhes as oportunidades que teriam se vivessem no campo. A criança parqueana não escala montanhas, mas sobe nas escadas verticais. Não trepa em árvores - porque a ela se deve ensinar também o amor e o carinho para com as árvores - mas equilibra-se e caminha nas escadas horizontais, como se passasse de galho a galho nas árvores do campo. Não monta a cavalo, mas balança-se nos aparelhos e gira nos carrosséis. (MIRANDA, I945, p. 49).

De maneira mais contundente, a natureza é justificada no documento elaborado

I6 Uma perspectiva do terreno e da vegetação de um parque infantil pode ser apreendida em fotografias do livro O significado de um parque infantil em Santo Amaro, de Miranda (I938), disponível na Biblioteca do IEB. 
por Fernando de Azevedo, o qual considerava a necessidade de promoção de educação higiênica. Para isso uma das medidas sugeridas era "a installação de modesto estabelecimento balneario e de pequena piscina (que) serviria para incutir, em crianças, habitos de asseio e de exercicio, e contribuir, por essa fórma, para 'o melhoramento da hygiene de milhares de familias"' (AZEVEDO, I930, p. 78-79). Desse modo, a higiene da cidade, por meio, inicialmente, do controle das várzeas, bem como de produção de zonas verdes entrecortando os bairros operários e suas chaminés que se formavam no meio urbano, também deveria alcançar a higiene de cada um, a começar pelas crianças.

A natureza foi considerada por essa política como um ambiente ideal para a prevenção da saúde e a cura de doenças, além de contribuir para o fortalecimento e a educação do corpo, por intermédio de exercícios físicos como a ginástica, o esporte, os jogos e as práticas terapêuticas. Portanto, os parques foram importantes para integrar o imaginário de natureza curativa à educação (DALBEN, 20I6; SOARES, 20I6; SOARES; SANTOS NETO, 20I8).

No que concerne à relação entre educação e infância naquele período, salientamos ainda o trabalho de Danailof (2006; 2013). A pesquisadora buscou compreender a educação do corpo nos parques infantis, evidenciando que se configuraram como espaços capazes de alterar as experiências corporais, modificando substancialmente a educação de crianças que viviam nos centros urbanos no país, a partir do início do século XX.

À infância, conforme se pode constatar nas fontes delimitadas em nossa pesquisa, foi dedicada uma atenção especial no âmbito dessa nova política. Note-se que, no contexto da ordem industrial em estruturação, crianças e jovens formavam uma parcela em risco. Ao mesmo tempo que, desde Fröbel (I982), na primeira metade do século XIX, já se considerava a necessidade de estímulos e atividades lúdicas para assegurar seu bom desenvolvimento, as ruas degradadas pelas indústrias, automóveis, bondes e outras tecnologias não ofereciam mais as condições adequadas para as brincadeiras, jogos e socialização entre pares. Diante desse paradoxo se fez necessária a especialização de uma tipologia de espaços recreativos, que o urbanismo emergente viria a atender. O Projeto Parques Infantis de São Paulo representou, como veremos em seu percurso, um bem-sucedido programa de educação e recreação sem precedentes (NIEMEYER, 2002).

Para Fernando de Azevedo, o Projeto Parques Infantis era parte de uma política educacional mais ampla, que viria a promover a educação física como um elemento

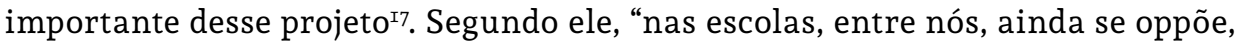
quando deveriam alliar-se para a mesma finalidade educativa, o estudo ao jogo, e a immobilidade e o silêncio á expansão ruidosa do movimento e ás estouvadas alegrias infantis" (AZEVEDO, I930, p. 6I). A proposição de Fernando de Azevedo enfatiza, assim, uma perspectiva para além dos benefícios da natureza, como provedora de educação higiênica e preservação social diante dos efeitos da cidade consumida pela

I7 Estudos anteriores já analisaram o interesse de Fernando de Azevedo pela educação física, entre eles o de Soares (I990) e o de Pagni (I994), evidenciando a importância desse intelectual para a área, sobretudo para sua justificação e inclusão no currículo escolar no Brasil, de forma sistemática a partir do início do século XX. 
indústria e comércio. A finalidade educativa dos parques se baseava em uma visão renovadora que valoriza a educação física como parte da educação, destacando a prática do jogo e da brincadeira como atividades educacionais relevantes. $\mathrm{O}$ autor enfatiza que novos conhecimentos sobre a psicologia infantil identificaram a importância do jogo para o desenvolvimento das crianças e, portanto, essas devem experimentar em seu cotidiano a liberdade para jogar.

Contudo, instrutores dos parques deveriam mediar preferencialmente os jogos relativos às tradições, evitando "jogos esportivos, francezes ou inglezes, que, pouco adequados á primeira edade, podem determinar perturbações physiologicas" (AZEVEDO, I930, p. 82). Queria o educador que os mesmos servissem a uma obra de restauração dos jogos nacionais, evitando o seu esquecimento diante da modernização, bem como do que ele denominou de distrações sedentárias, como o cinema e o teatro. Esse aspecto sugere que o pensamento de Fernando de Azevedo, ao mesmo tempo que se fundamentava na renovação da educação, buscava preservar tradições e seus valores na educação de crianças.

Nesse sentido, cabe ressalvar que outros estudos evidenciaram o vínculo dos parques infantis a uma perspectiva de controle social de crianças paulistas, especialmente dos filhos de imigrantes que necessitavam de assistência médica, dentária e alimentar. O caráter disciplinador e autoritário de tais instituições era, de acordo com Paula (I997), camuflado pelo ambiente recreativo. Com efeito, Miranda (I940) protagonizou pesquisa nos parques, destacando a necessidade da organização dos jogos por parte dos adultos, mais precisamente, por especialistas, como instrutores e professores de educação física. Essa organização se estruturou em diversos elementos, como a seleção do local, do material, do número de participantes, bem como da classificação dos jogos conforme a faixa etária. Sob a "sombra das árvores", as crianças deveriam ser protegidas, participando de práticas pedagógicas voltadas à formação da consciência nacionalista, bem como de ideais de solidariedade, obediência e determinação. Desse modo, os parques mediavam uma política de prevenção da criminalidade e do ócio delinquente infantil (SANDRONI, I998; RAFFAINI, 200I). Visavam sobretudo contribuir para a formação de uma identidade nacional entre os descendentes de imigrantes, bem como promover a docilização dos corpos infantis para o trabalho na fábrica (GUEDES, 2006; DALBEN, 2009). Essa perspectiva estabelece clara correspondência com aquela da lapidação da criança na formação do adulto moderno, já indicada por Benjamin (I984).

Interessante notar, que, de acordo com a análise de Niemeyer (2002), o projeto dos parques infantis era marcado por uma diversidade de discursos vigentes naquele período. Por isso sua compreensão perpassa visões educacionais controversas, ou seja, por um lado, de cunho progressista e, por outro, conservador. Os parques configuraram instituições pioneiras, conforme anteriormente assinalado, que promoviam o acesso da população infantil à cultura e à educação, destacando-se brincadeiras e atividades artísticas. Ao mesmo tempo, representaram políticas de controle social das crianças. Essa dualidade favoreceu a propagação desse projeto em diferentes ambientes políticos da municipalidade de São Paulo. 


\section{BRINCADEIRAS E JOGOS AO AR LIVRE}

Ao abordarmos como fonte de nosso estudo a coleção de desenhos infantis presentes no acervo de Mário de Andrade, logo observamos que há inúmeros temas que foram representados pelas crianças. São cenários urbanos, como edificações, casas, meios de transporte, animais, flores, frutas, legumes, figuras humanas, ambientes domésticos, móveis, jardins, paisagens naturais, objetos pessoais, personagens de histórias em quadrinhos, bandeiras, utensílios, entre outros. Ao tomar esses desenhos como fonte, nosso objetivo foi identificar em seus traços brincadeiras e jogos, considerando os parques infantis como espaços projetados para a educação das crianças de forma mais ampla, onde a recreação e os divertimentos têm lugar garantido.

Em primeiro plano, destacam-se representações de brincadeiras tradicionais, como, por exemplo, empinar papagaio (Coleção de Artes Visuais IEB/USP, Fundo Mário de Andrade, MA-DI-I873) e pular corda (Coleção de Artes Visuais IEB/USP, Fundo Mário de Andrade, MA-DI-I6I8 e MA-DI-2023). Há muitas variações dessa última, que requer coordenação motora ampla, força de membros, resistência aeróbica e ritmo. Na coleção examinada representou-se a modalidade tanto individual de pular corda, como em grupo. Trata-se de uma brincadeira que parece resistir ao tempo, pois até hoje é indicada em pesquisas com crianças como uma das preferidas (WIGGERS; OLIVEIRA; FERREIRA, 20I8).

Os desenhos registraram também brincadeiras nos equipamentos que os parques infantis ofereciam, destacando o balanço (Coleção de Artes Visuais IEB/USP, Fundo Mário de Andrade, MA-DI-0392 e MA-DI-0368) e o chamado “passo do gigante", uma espécie de carrossel que gira com o impulso de grandes passadas dadas pelas próprias crianças (Coleção de Artes Visuais IEB/USP, Fundo Mário de Andrade, MA-DI-04I6). Como sabemos, esses brinquedos exercem forte atração entre elas, pois proporcionam desafios corporais que mobilizam qualidades físicas como força e resistência, ao mesmo tempo que oferecem alegria e prazer. Os parques norte-americanos, precursores desse tipo de equipamentos e atividades, foram os primeiros a construir a caixa de areia como um lugar de brincadeiras e jogos (MERO, I908). Tais espaços, pouco a pouco, foram se transformando no que veio a ser denominado de playground, um terreno equipado com gangorra, escorregador, carrossel e tanque de água, além de outros brinquedos, produzindo ainda maior adesão por parte da meninada. Esses equipamentos projetados especialmente para as crianças ofereceram uma novidade nos ambientes urbanos no início do século XX, vulgarizando-se ao longo do tempo. Todavia, se por um lado os balanços ainda estão presentes nos parquinhos de hoje em dia, por outro não encontramos mais exemplares do passo do gigante. Ambos provocam aquela sensação de vertigem, demonstrada em risos ou gargalhadas, como sinais ambíguos do relaxamento ou da ansiedade.

Enquanto objeto de representação nos desenhos encontramos, além das brincadeiras tradicionais e aquelas realizadas nos equipamentos, a presença de jogos esportivos, como, por exemplo, o voleibol e o futebol. Sem dúvida que essas práticas esportivas encontraram grande possibilidade de desenvolvimento dada a topografia dos parques infantis, que se caracterizavam por amplos espaços abertos e terrenos planos, conforme anteriormente assinalado. 
Segundo Linhales (2009), a partir do início do século XX, notou-se a vulgarização de atividades esportivas no país, que serviram de referência para o que a autora denominou de "forma escolar do esporte". O chamado "surto dos sports" que se propagou no país foi, conforme a autora, um conjunto de experiências culturais tomadas como conteúdo para a constituição de saberes de uma nova escola, concorrendo para o processo de modernização da educação nacional. O projeto cultural de escolarização do esporte no país, ressalte-se, teria sido promovido pela Associação Brasileira de Educação (ABE). Dessa forma, dava-se visibilidade pública a comportamentos e condutas entendidas como modelares para a vida na sociedade moderna. Carvalho (2003, p. 63) acentuou que, nesse contexto, "o esporte e a vida saudável simbolizavam a energia, o vigor, a força, a operosidade, signos de progresso inscritos no corpo que conhece o movimento adequado e útil para cada ato".

Contudo, no projeto original dos parques, Fernando de Azevedo recomendou que esses espaços deveriam promover a restauração de jogos e brinquedos nacionais. "Não ha brinquedo ou jogo importado, cujas qualidades educativas sobrelevem ás os jogos locaes" (AZEVEDO, I930, p. 82). Por outro lado, ainda, ao mesmo tempo que o pioneiro da educação defendia uma representação tradicional, contemporizava, pois o convívio entre o nacional e o estrangeiro parecia inevitável, refletindo um dilema experimentado pelos modernistas brasileiros (JOBIM, 20I7). Observa-se, portanto, um movimento contraditório na história, a exemplo do considerado por Chartier (2002) e Certeau (20I4). Atravessando o século XX, o futebol viria a se tornar uma preferência observada nos pátios escolares, praças e ruas.

Todos os paizes cultos esforçam-se por conservar e propagar seus jogos próprios, que devem compor a base do seu systema, enriquecido, evidentemente, de todos aquelles que, pela experiência universal, são dignos de ser incorporados ao patrimônio dos jogos nacionais. (AZEVEDO, I930, p. 82).

De outro modo, em conformidade com as orientações do projeto de Fernando de Azevedo, as brincadeiras também foram lembradas no âmbito de manifestações folclóricas. É o caso da "Nau Catarineta"18, que se caracteriza como um bailado dramático, de origem portuguesa, composto de cinco partes, tal como uma suíte. Narra uma história em torno de imigrantes portugueses que vieram ao Brasil em busca de melhores condições de vida. A saga da caravela ao atravessar o Atlântico é cantada em verso trágico, pois a nau demora a chegar ao seu destino, ameaçando de morte os seus tripulantes, de fome e sede. A certa altura um diabo atormenta o capitão, até que a chegada de um anjo afugenta o maldito. Ao fim, a terra prometida se avista e todos se salvam (ANDRADE, I94I). Identificamos muitas caravelas desenhadas na coleção, o que provavelmente reflete essa vivência da brincadeira cantada (Figura I). 


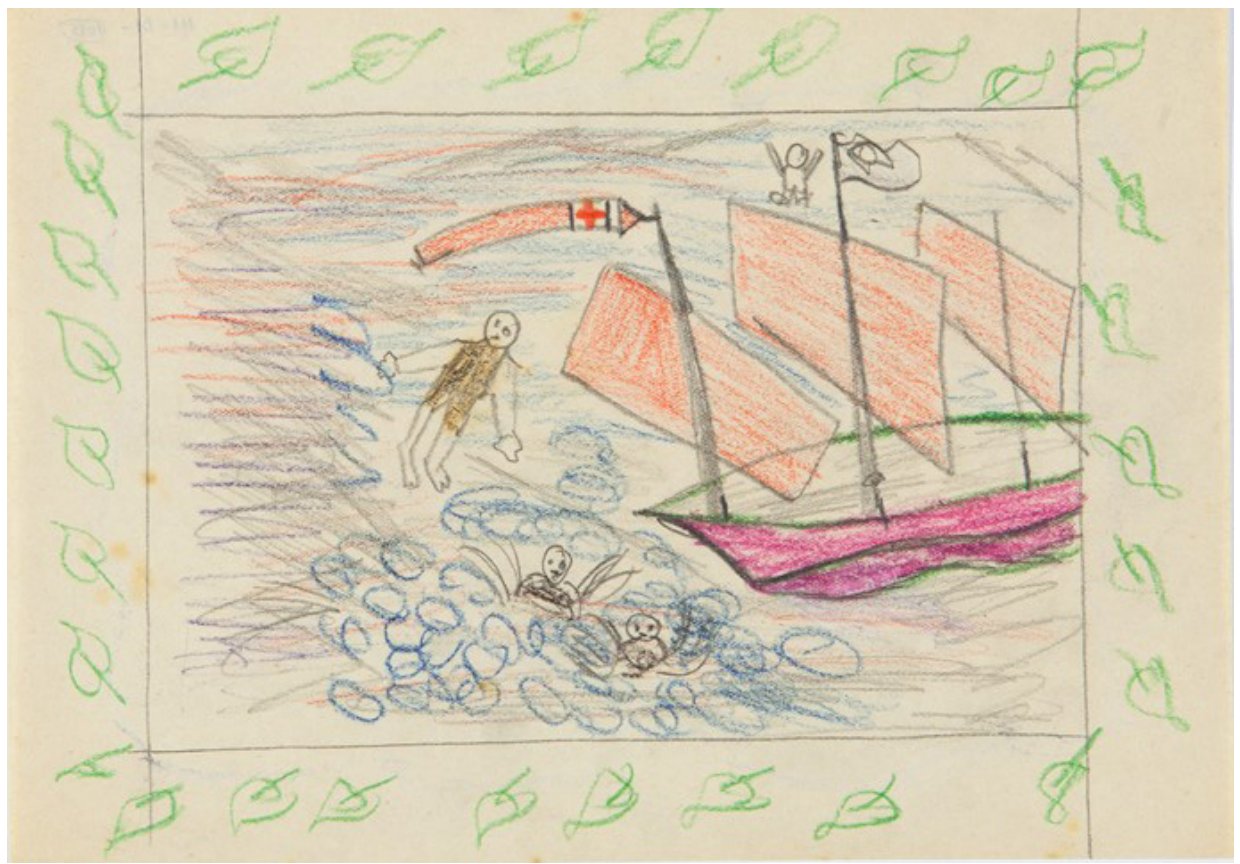

Figura I - Desenho representando a saga "Nau Catarineta”, destacando o perigo do mar que se materializa mediante as tempestades. Fonte: Coleção de Artes Visuais IEB/USP, Fundo Mário de Andrade, MA-DI-Io85

A literatura infantojuvenil do período divulgava o drama dos marujos, vulgarizando manifestações típicas como essa. Na Biblioteca do IEB/USP, no Fundo Mário de Andrade, encontramos um exemplar da Contribuição do folk-lore brasileiro para bibliotheca infantil, contendo uma reprodução completa do poema formado por dezenove estrofes (PINTO, I907, p. I86).
Vinha a náu Catharineta
Já farta de navegar,
Sete anos e um dia
Era nas ondas do mar
[...]
Vamos, vamos meu gageiro,
Meu gageirinho real!
Ei-nos em terras d'Hespanha,
Areias de Portugal!

Identificamos outros vestígios dessa expressão que alimentava a imaginação infantil. Cenas do bailado "Nau Catarineta" dramatizadas pelas próprias crianças no âmbito de atividades dos parques infantis também foram registradas em fotografias (Acervo Fotográfico do Museu da Cidade de São Paulo, Tombo DC/oooorzo/A). Para 
além desses traços, de acordo com um "programa"'9 encontrado na coleção de desenhos, em I7 de outubro de I937, teria acontecido uma apresentação dessa estória. Interessante notar que o documento ressalta a necessidade de adaptar o bailado tradicional ao nosso idioma, estabelecendo a pronúncia cantada da língua brasileira. Sobretudo, observam-se as possibilidades das crianças, acompanhando tendências emergentes da psicologia do desenvolvimento.

Nos nossos bailados tradicionais, com exceção única no chamado "Pastoril”, não entram mulheres. Mas como não se trata de executar a tradição tal como ela persiste ainda entre as populações nordestinas, mas de realizar uma adaptação de acordo com as exigências infantís e as nossas possibilidades atuais, faremos entrar também meninas, que formarão uma espécie de côro a parte, comentando a representação, segundo o processo dos côros da tragédia grega. (Coleção de Artes Visuais IEB/-USP, Fundo Mário de Andrade, MA-DI- I277).

Esse bailado fora recuperado por meio de pesquisas folclóricas, segundo Filizzola (2002), pelo próprio Mário de Andrade para compor o repertório de atividades dos parques infantis. Considerando sua origem portuguesa, bem como sua fixação em diversas regiões do Brasil desde o século XVIII, de certa forma, o mesmo representava uma tentativa de contribuir para nacionalização dos filhos de imigrantes. Pretendeu-se, assim, reviver costumes tradicionais, por meio de jogos e brincadeiras, evitando o contágio e a influência das massas populares de imigrantes na cultura brasileira.

Se, por um lado, nota-se o movimento de abrasileiramento da música e adaptação de peças clássicas, por outro, Mário de Andrade não parecia concordar com o processo de moralização infantil mediado por manifestações de caráter folclórico como essa. Por essa razão, insistiu que trechos tidos como imorais fossem mantidos naquela adaptação voltada às crianças parquianas.

Até que ponto um texto popular pode ser considerado prejudicial à constituição do indivíduo futuro? Até que ponto a moralização dos textos não os tornará rançosos, estupidamente rígidos, repulsivos ao recreio infantil e provocadores mesmo de represálias e dasabafos psicológicos noutro lugar mais desgovernado?. (DEPARTAMENTO DE CULTURA, I938, p. IO).

Há muitos tipos de navios, barcos e veleiros, de diversos tamanhos, cores e formatos, entre os desenhos das crianças paulistas, filhas de imigrantes, da década de I930. Diversas inscrições como, por exemplo, "Um navio europeo que vem para o Brasil”, evidenciam claramente o imaginário do imigrante (Coleção de Artes Visuais IEB/-USP, Fundo Mário de Andrade, MA-DI-03I9). Para além desses dados, o que mais poderia tanto estimular a representação do mar e seus elementos? A grande quantidade de embarcações representadas interroga o apreciador da coleção, pois São Paulo não está à beira-mar (Figura 2).

I9 Provavelmente, trata-se do programa do I Congresso de Língua Nacional Cantada. 


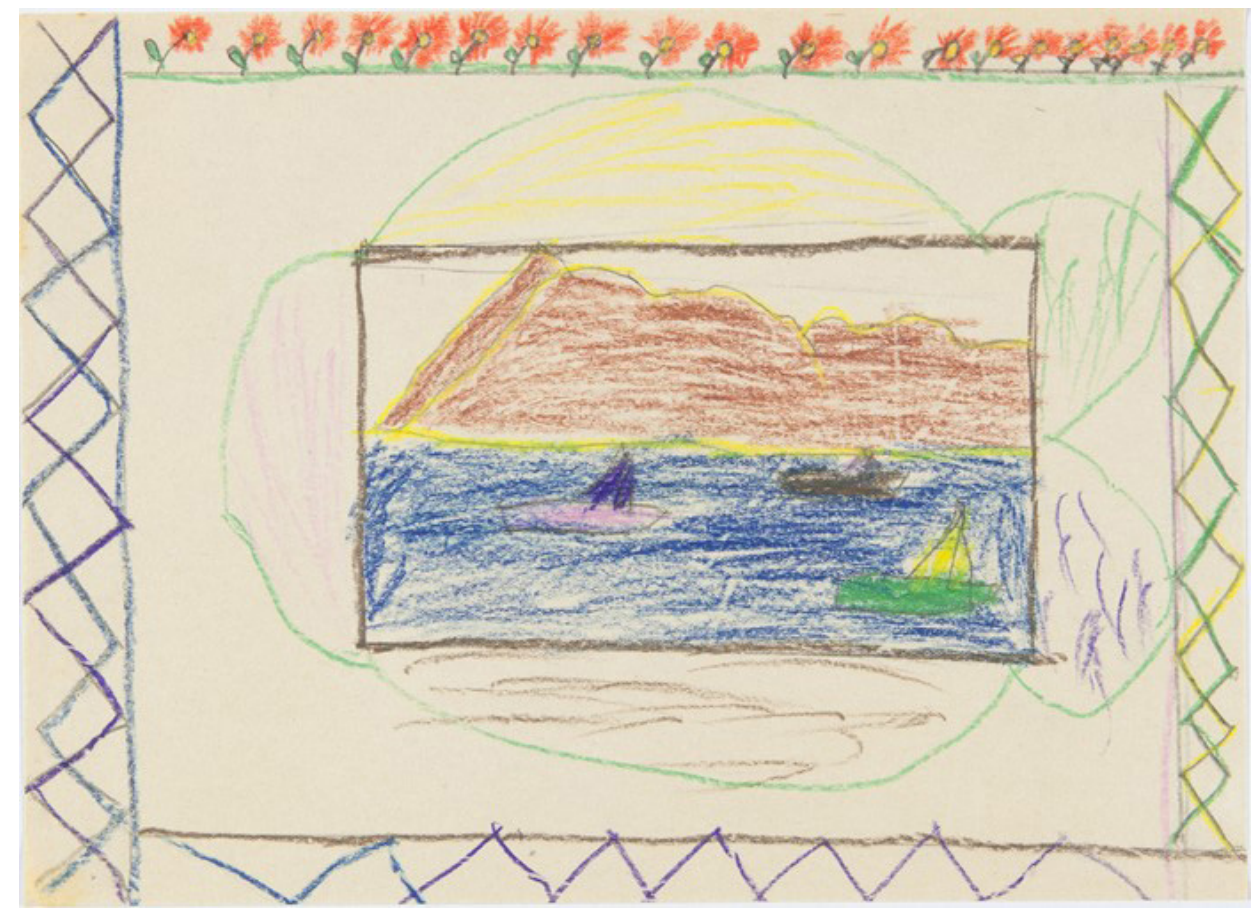

Figura 2 - Desenho representando uma paisagem marítima. Fonte: Coleção de Artes Visuais IEB/USP, Fundo Mário de Andrade, MA-DI-I392

O livro de Nicanor Miranda (I938) intitulado O significado de um parque infantil em Santo Amaro suscita outras interpretações, pois é ilustrado por fotografias do entorno do parque, entre elas, da represa de Santo Amaro, do elegante Clube de Iatismo e dos barcos velejando em regata nas águas calmas. A represa, conforme evidenciou Jorge (20I6), era tida como um espaço privilegiado para recreação e esportes náuticos desde a sua construção no início do século XX. Mas não apenas essa represa oferecia o contato da população paulista com a água. Os rios Tietê e Pinheiros, que cortam a capital, foram palco privilegiado de diversas atividades aquáticas e esportivas como parte da cultura vibrante do início do século XX (SEVCENKO, I992; NICOLINI, 200I; JORGE, 2006; SANT'ANNA, 2007).

Outra associação pode também ser considerada entre os temas marítimos, presentes em grande quantidade nos desenhos das crianças paulistas da década de I930, e a cultura visual infantil. Trata-se de levar em conta a literatura infantojuvenil do período e, nesse caso, mais especificamente, os pequenos livros de colorir, que faziam parte das bibliotecas dos parques infantis. O contato com essa literatura foi confirmado por uma parquiana em entrevista concedida a Filizzola (2002, p. 228): "a gente brincava, ia para a biblioteca, pois por mais que você não sabia [sic] ler tinha aqueles livros que você pintava... eles davam tudo!”. Exemplares deles podem ser encontrados no Fundo Mário de Andrade da Biblioteca do IEB/USP, contendo ilustrações de mar, rios, lagos, barcos, peixes, casas, frutas, flores, além de paisagens (Figura 3). Essas imagens podem ter sido uma referência visual no processo de busca 
de soluções que cada criança empreendeu para realizar seu desenho (MARTINS; TOURINHO, 20IO).

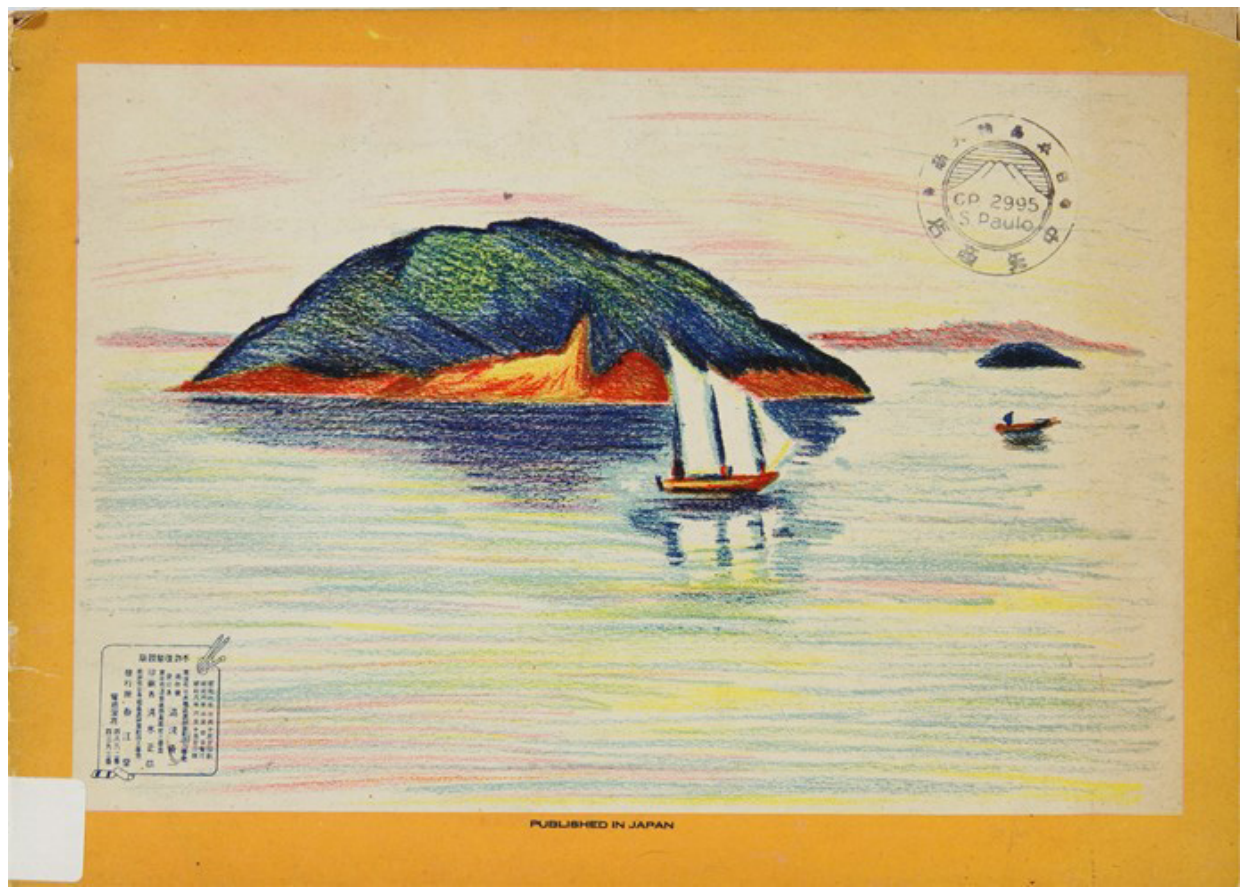

Figura 3 - Contracapa de livro de colorir da Biblioteca do IEB/USP, Fundo Mário de Andrade. Uma paisagem marítima está representada. Fonte: Kurepasu Jishû gachô, v. I, 3, 5, 6 (YUASA, I933)

A partir da observação dos desenhos é possível inferir que os elementos da natureza, tais quais os raios de sol ou a placidez da lua e das estrelas, estão presentes na maioria dos trabalhos em que as águas de rios e do mar surgem em diferentes composições. As muitas formas das nuvens que cobrem o céu são também ali representadas, assim como as árvores, os pássaros, as borboletas, além das montanhas, compondo uma cultura visual do desenho infantil. A natureza e seus elementos, contudo, não surgem somente na composição das paisagens ou em cenas individualizadas, mas também no formato de jardins ou quintais, em contextos urbanos, remetendo, assim, à ideia de uma "natureza controlada" (DALBEN; SOARES, 2OII; SOARES, 20I6).

Da mesma forma, o ambiente da cidade, de indústrias e de tecnologias, sugeria a entrada do país em um mundo modernizado e de costumes renovados. A tradição simbolizava um paradoxo. Por um lado, o passado deveria ser esquecido para que a modernidade pudesse ser projetada. Por outro, para muitos educadores da época, o desabrochar de um Brasil novo deveria ser "alicerçado num povo ativo, jovem e saudável - mas que conta com uma tradição a ser preservada” (BATISTA, 2002, p. I5). Nos parques infantis, a formação de hábitos pautados em valores nacionais era 
permeada por essa ambiguidade. "A arquitetura neocolonial, as plantas e árvores brasileiras, em conjunto com os modernos aparelhos arquitetônicos, como 'argola a uma altura graduada conforme o tamanho das crianças', realçam um silencioso discurso" (DALBEN; DANAILOF, 2009, p. I63). Desse modo, ao tempo que os desenhos infantis registram a natureza como uma dimensão significativa da vida, expressam um período cruzado por elementos culturais tecnológicos, ilustrados pelos novos meios de transporte que se desenvolviam no período (Figura 4).

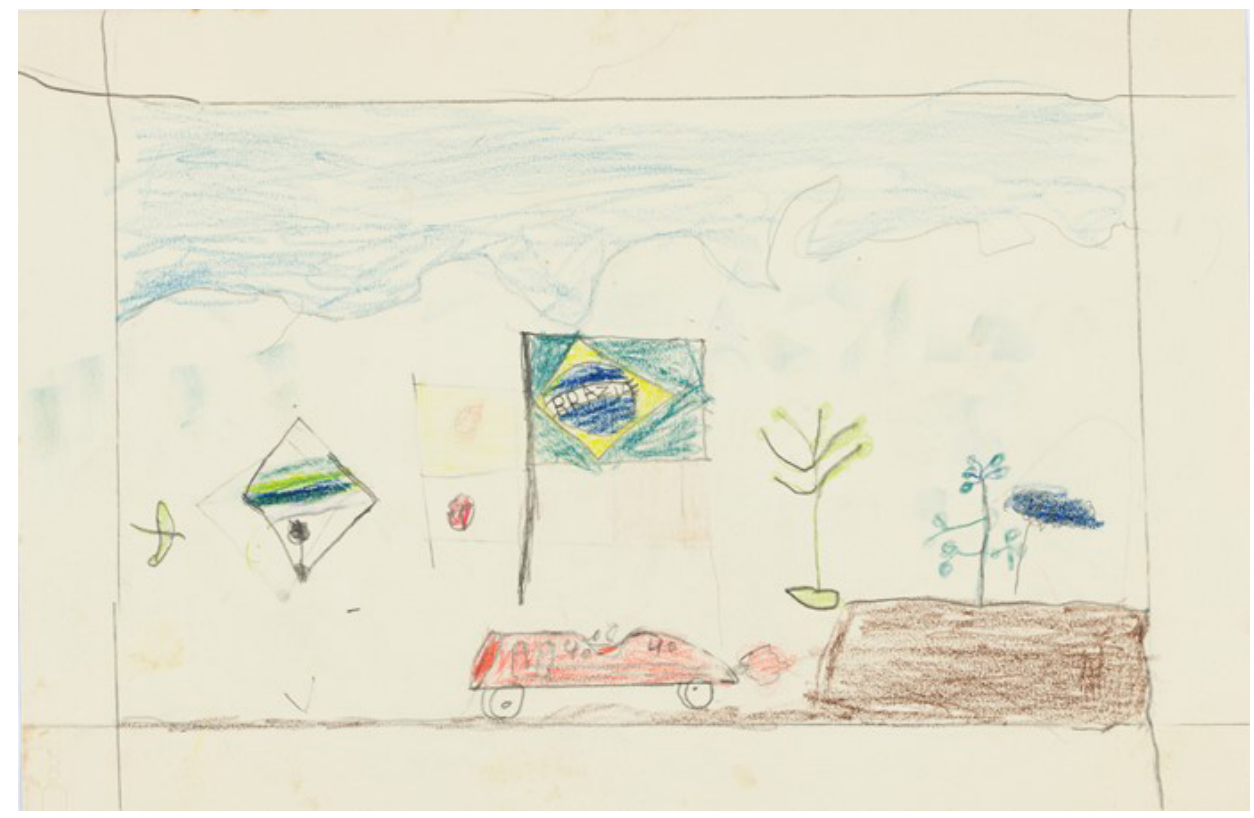

Figura 4 - Desenho representando um carro de corrida, além de outras figuras como a bandeira brasileira, céu e vegetação. Fonte: Coleção de Artes Visuais, Fundo Mário de Andrade, MA-DI-0066.

O intenso processo de urbanização do período parecia provocar, em contraste, uma reação no sentido de valorização da experiência da natureza e da vida ao ar livre, gerando uma dinâmica histórica de tensões e novas perspectivas. Desse modo, a partir da análise dos desenhos, foi possível considerar a natureza e seus elementos como uma dimensão que dialoga, de modo profundo, com tudo o que a cidade de São Paulo significava no que concerne ao progresso tecnológico, o que pode ser constatado pela presença constante de meios de transporte, assim como de grandes obras da arquitetura. Em uma cidade banhada por muitos rios, as pontes e os barcos não ficaram ausentes dos desenhos analisados, assim como aviões, trens, bondes, ônibus e carros, que se misturam com a fumaça das fábricas, flores e frutas, jardins e montanhas. 


\section{CONSIDERAÇõES FINAIS}

O Projeto Parques Infantis de São Paulo teve lugar de relevo nas ações do Departamento de Cultura e Recreação, sob a gestão de Mário de Andrade, entre I935 e I938. Nos anos subsequentes, sua repercussão deu-se em prol de uma política da educação infantil. Como assinalamos, a pedagogia dos parques articulava a natureza e seus elementos à educação higiênica e assistência infantil, bem como a brincadeira e o jogo como atividades fundamentais para a socialização, a educação estética e a formação da identidade nacional das crianças paulistas. Nesse ambiente, elas foram estimuladas a vivenciar brincadeiras, jogos e expressões artísticas diversas e, assim, exercer sua imaginação e criatividade. Os desenhos da coleção de Mário de Andrade, por sua vez, também provocam a nossa imaginação, colocando-nos em contato com a formidável memória infantil.

Destacamos, a partir da análise da coleção, que foram representadas brincadeiras tradicionais, brincadeiras nos equipamentos dos parques, jogos esportivos, bem como manifestações folclóricas, evidenciando interfaces entre tradicional e novo. Outros aspectos ressaltaram, levando em conta a presença de elementos da natureza nos traços, além de figuras ligadas ao desenvolvimento tecnológico que marcaram significativamente o período.

O desenho, ato estritamente humano e uma das manifestações da infância, realiza a integração entre pensamento e imaginação, podendo expressar a cultura infantil de um tempo e de um lugar. A coleção por nós apreciada sugere que diferentes mediações permearam os motivos das ilustrações produzidas pelas crianças paulistas, pois evidenciamos a presença de brincadeiras, esportes, manifestações culturais, assim como a linguagem visual acessível, por exemplo, em livros de colorir. A expectativa das instrutoras dos parques também teria influenciado a produção gráfica, assim como as origens familiares, além da própria idade. Mais do que determinar quais dessas mediações prevaleceram nas decisões e possibilidades das crianças, a análise da coleção evidencia escolhas que elas fizeram diante de suas experiências culturais e sociais. Salientamos, por fim, que o desenho é, também, uma brincadeira, dimensão não esquecida em nossa análise, pois representa o testemunho de um tempo e lugar.

\section{SOBRE AS AUTORAS}

INGRID DITTRICH WIGGERS é professora do Programa de Pós-Graduação em Educação e do Programa de Pós-Graduação em Educação Física da Universidade de Brasília (UnB) e líder do Imagem - Grupo de Pesquisa sobre Corpo e Educação da Faculdade de Educação Física (FEF/UnB).

E-mail: ingridwiggers@gmail.com

https://orcid.org/o0o0-000I-54I2-702I 
CARMEN LUCIA SOARES é professora do Programa de Pós-Graduação em Educação da Universidade Estadual de Campinas (Unicamp), membro do Focus - Grupo de Pesquisa sobre Educação, Instituições e Desigualdade da Faculdade de Educação (FE/ Unicamp) e pesquisadora do Conselho Nacional de Desenvolvimento Científico e Tecnológico (CNPq).

E-mail: carmenls@unicamp.br

https://orcid.org/oooo-0002-4347-I924

\section{REFERÊNCIAS}

ACERVO Fotográfico do Museu da Cidade de São Paulo. Secretaria Municipal de Cultura. Acervos culturais e artísticos da cidade de São Paulo. Disponível em: 〈http://www.acervosdacidade.prefeitura.sp.gov. br/PORTALACERVOS/ExibirAcervo.aspx?cdAcervo=IO〉. Acesso em: set. 2019.

AMIN, Raquel Carneiro; REILY, Lucia. Artistas colecionadores de desenhos infantis. In: ENCONTRO DE HISTÓRIA DA ARTE, 4., 2008, Campinas, Anais... Campinas: IFCH/UNICAMP, 2008. p. 36-42. 2008. Disponível em: <https://www.ifch.unicamp.br/eha/atas/2008/AMIN,\%20Raquel\%20Carneiro\%20 -\%20IVEHA.pdf $>$. Acesso em: 5 nov. 2018.

ANDRADE, Mário de. Pintura infantil. Diário Nacional, São Paulo, 23 nov. I930. . A nau catarineta. Revista do Arquivo Municipal. São Paulo, v. 73, jan. I94I, p. 6I-75.

AZEVEDO, Fernando. A evolução do esporte no Brasil. São Paulo/Cayeiras/Rio de Janeiro: Melhoramentos, I930.

BATISTA, Marta Rossetti. Introdução. Revista do Patrimônio Histórico e Artístico Nacional: Mário de Andrade, Brasília: Iphan, n. 30, 2002, p. 6-23. Disponível em: <http://portal.iphan.gov.br/uploads/publicacao/ RevPat3o_m.pdf >. Acesso em: 5 nov. 2018.

BENJAMIN, Walter. Reflexões: a criança, o brinquedo, a educação. São Paulo: Summus, I984.

BRITO, Priscila F. "Foi respeitada a expressão da criança quando disse o que fez"? - artes nos parques infantis através das fotografias de Benedito Junqueira Duarte. 20I6. I62 f. Dissertação (Mestrado em Educação). Faculdade de Educação, Universidade de São Paulo, 2016.

CAVALLO, Dominick. Muscles and morals: organized playgrounds and urban reform, I880-I920. Philadelphia: University of Pennsylvania, I98I.

CARVALHO, Marta M. Chagas de. A escola e a república e outros ensaios. Bragança Paulista: Universidade São Francisco, 2003.

CERTEAU, Michel. A invenção do cotidiano: artes de fazer. 22 ed. Petrópolis: Vozes, 20I4.

CHARTIER, Roger. A história cultural: entre práticas e representações. Algés: Difusão Cultural, 2002.

COUTINHO, Rejane G. A coleção de desenhos infantis do acervo Mário de Andrade. 2002. I44 f. Tese (Doutorado em Comunicação e Artes). Escola de Comunicações e Artes, Universidade de São Paulo, 2002.

DALBEN, André. Educação do corpo e vida ao ar livre: natureza e educação física em São Paulo (I930-I945). 2009. I7o f. Dissertação (Mestrado em Educação Física). Faculdade de Educação Física, Universidade Estadual de Campinas, 2009.

. Notas sobre a cidade de São Paulo e a natureza de seus parques urbanos. Urbana: Revista Eletrônica do Centro Interdisciplinar de Estudos sobre a Cidade, Campinas, v. 8, n. 2 [I3], maio/ago. 20I6, p. 3-27. 
DALBEN; André; DANAILOF, Kátia. Natureza urbana: parques infantis e escola ao ar livre em São Paulo (I930-I940). Revista Brasileira de Ciências do Esporte, Campinas, v. 3I, n. I, set. 2009, p. I63-I77.

DALBEN, André; SOARES, Carmen Lúcia. Uma educação pela natureza: vida ao ar livre e métodos terapêuticos nas colônias de férias infantis do estado de São Paulo (I940). Pro-Posições, Campinas, v. 22, n. I, jan./abr. 20II, p. I67-I82.

DANAILOF, Kátia. Crianças na trama urbana: as práticas corporais nos parques infantis de São Paulo dos anos I930. 2006. I76 f. Tese (Doutorado em Educação). Faculdade de Educação, Universidade Estadual de Campinas, 2006.

. A "educação physica" nos parques infantis de São Paulo (I935-I938). Movimento, Porto Alegre, v. I9, n. 2, abr./jun. 20I3, p. I67-I84. Disponível em: <https://seer.ufrgs.br/Movimento/article/ view/32324/25259>. Acesso em: 5 nov. 2018.

DEPARTAMENTO DE CULTURA. Divisão de Educação Física e Recreio. A Marujada. São Paulo, I938.

DIAS, Silvana Moreli Vicente. Crônicas e cartas como laboratório multidisciplinar: a infância como topos e o esboço de um éthos da província do Modernismo brasileiro. Revista do Instituto de Estudos Brasileiros, São Paulo, n. 67, ago. 2017, p. 204-220. Disponível em <http://www.scielo.br/scielo.php?scrip$\mathrm{t}=\mathrm{sci}$ _arttext\&pid=So020-38742017000200204\&lng=en\&nrm=iso\&tlng=pt $\rangle$. Acesso em: 5 nov. 2018.

FARIA, Ana Lucia Goulart. A contribuição dos parques infantis de Mário de Andrade para a construção de uma pedagogia da educação infantil. Educação er Sociedade, Campinas, v. 20, n. 69, dez. I999a, p. 60-9I. Disponível em: <http://www.scielo.br/scielo.php?script=sci_arttext\&pi$\mathrm{d}=$ SoIOI-7330I999000400004\&lng=en\&nrm=iso\&tlng=pt $>$. Acesso em: 5 nov. 2018.

. Educação pré-escolar e cultura: para uma pedagogia da educação infantil. Campinas: Cortez/Unicamp, I999b.

FEIX, Eneida. Lazer e cidade na Porto Alegre do início do século XX: a institucionalização da recreação pública. Io8 f. Dissertação (Mestrado em Educação Física). Escola de Educação Física, Universidade Federal do Rio Grande do Sul, 2003.

FERREIRA, Flávia Martinelli; WIGGERS, Ingrid Dittrich. Childhood and urbanity in São Paulo city’s playgrounds. Educação e Pesquisa, São Paulo, v. 45, 20I9. Disponível em: <http://www.scielo.br/pdf/ ep/v45/en_I5I7-9702-ep-45-eI94024.pdf $>$. Acesso em: I5 set. 20I9.

FILIZZOLA, Ana Carolina Bonjardim. Na rua, a "troça", no parque, a troca: os parques infantis da cidade de São Paulo na década de I930. 2002. 233 f. Dissertação (Mestrado em Educação). Faculdade de Educação, Universidade de São Paulo, 2002.

FONSECA, João Pedro da. Educar, assistir, recrear: um estudo de objetivos da pré-escola. São Paulo: Faculdade de Educação, Universidade de São Paulo, I98I.

. O cinqüentenário dos parques infantis de São Paulo: I935/I985. Revista da Faculdade de Educação, São Paulo, v. II, n. I-2, p. I35-I48. jan./dez, I985. Disponível em: 〈https://www.revistas.usp.br/rfe/ article/view/3334I/36079>. Acesso em: 5 nov. 2018.

FRÖBEL, Friedrich Wilhelm August. Kommt, lasst uns unsern Kindern leben! Band 3. Berlin: Volkseigener, I982.

GOBBI, Marcia. Mário de Andrade e os desenhos das crianças pequenas: olhares de "turista aprendiz". In:

FREITAS, Marcos Cezar de (Org.). Desigualdade social e diversidade cultural na infância e na juventude. São Paulo: Cortez, 2006, p. I75- 205.

. Desenhos de outrora, desenhos de agora. Mário de Andrade colecionador de desenhos e desenhista. São Paulo: Annablume, 2011 .

. Desenhos e fotografias: marcas sociais de infâncias. Educar em Revista, Curitiba, v. I, n. 43, p. 
I35-I47, jan./mar. 20I2. Disponível em <http://www.scielo.br/scielo.php?script=sci_arttext\&pi$\mathrm{d}=$ SoI04-406020I2000I000Io\&lng=pt\&tlng=pt $\rangle$. Acesso em: 5 nov. 2018.

GUEDES, Lizandra. Novas velhas formas de dominação: os parques infantis e o novo projeto de dominação social. 2006. I79 f. Dissertação (Mestrado em Psicologia). Instituto de Psicologia, Universidade de São Paulo, 2006.

INAUGURA-SE hoje, ás Io horas, o "play-ground” do parque d. Pedro II. Diário Nacional, n. I.062, 25 de dezembro de 1930.

JOBIM, José Luís. Francesismo ou nacionalismo? Dilemas do modernismo brasileiro nas cartas dos anos I920. Revista do Instituto de Estudos Brasileiros, São Paulo, n. 68, dez. 20I7, p. 208-226. Disponível em: <http://www.scielo.br/scielo.php?script=sci_abstract\&pi$\mathrm{d}=$ Soo20-387420I7000300208\&lng=pt\&nrm=iso\&tlng=pt $>$. Acesso em: 5 nov. 2018.

JORGE, Janes. Tietê: o rio que a cidade perdeu, São Paulo, I980-I940. São Paulo: Alameda, 2006. . A represa do Guarapiranga e os esportes na região de São Paulo (I905-I963). In: SOARES, Carmen Lucia (Org.). Uma educação pela natureza: a vida ao ar livre, o corpo e a ordem urbana. São Paulo: Autores Associados, 20I6, p. I8I-204.

LINHALES, Meily Assbú. A escola e o esporte: uma história de práticas corporais. São Paulo: Cortez, 2009. MARTINS, Raimundo; TOURINHO, Irene (Org.). Cultura visual e infância: quando as imagens invadem a escola. Santa Maria: Universidade Federal de Santa Maria, 2010.

MEDA, Juri. Sgorbi e scarabocchi: guida ragionata alle collezioni storiche di disegni infantili. History of Education erChildren's Literature, Macerata, v. 2, n. I, 2007, p. 349-372. Disponível em: <http://hdl. handle.net/Ir393/377I4>. Acesso em: 5 nov. 2018.

. Los dibujos infantiles como fuentes históricas: perspectivas heurísticas y cuestiones metodológicas. Revista Brasileira de História da Educação, Maringá, v. I4, n. 3 (36), set.-dez. 20I4, p. I5I-I77. Disponível em <http:/periodicos.uem.br/ojs/index.php/rbhe/article/view/38897/pdf_4I >. Acesso em:5 nov. 2018.

MELLO, Luiz G. R. de Anhaia. Problemas de urbanismo: bases para a resolução do problema técnico. Boletim do Instituto de Engenharia, São Paulo, I929, p. 24-26.

MERO, Everett Bird. American playgrounds: their construction, equipment, maintenance and utility. Boston: American Gymnasia, I908.

MIRANDA, Nicanor. O significado de um parque infantil em Santo Amaro. São Paulo: Subprefeitura de Santo Amaro, I938.

. Técnica do jogo infantil organizado. Revista do Arquivo Municipal, São Paulo, v. 6, n. 74, out. I940, p. 7-7I.

. Origem e propagação dos parques infantis e parques de jogos. São Paulo: Departamento de Cultura, I94I.

. A harmonia entre o corpo e o espírito: ensaios de educação física. Rio de Janeiro: Imprensa Nacional, I945.

NICOLINI, Henrique. Tietê: o rio do esporte. São Paulo: Phorte, 200I.

NIEMEYER, Carlos Augusto da Costa. Parques infantis de São Paulo: lazer como expressão da cidadania. São Paulo: Annablume, 2002.

NIEMEYER, Carlos Augusto da Costa. Uma contribuição para a pesquisa em história do paisagismo: os parques infantis e as ressonâncias da tipologia reform park em São Paulo. Paisagens em Debate. São Paulo, n. 3, nov. 2005, p. I-I6. Disponível em: <http://www.fau.usp.br/depprojeto/gdpa/paisagens/ artigos/2005Niemeyer-ParquesIfantis.pdf >. Acesso em: 5 nov. 2018.

PAGNI, Pedro Angelo. Fernando Azevedo educador do corpo. Dissertação (Mestrado em Educação). Progra- 
ma de Pós-Graduação em História e Filosofia da Educação, Pontifícia Universidade Católica, São Paulo, I994.

PAULA, David Ferreira de. O treinamento físico da criança pobre no Estado Novo: a experiência do parque infantil na cidade de São Paulo. Pós-História: Revista de Pós-Graduação em História, v. 5, I997, p. I7I-I83.

PENNA, Maria Luiza. Fernando de Azevedo. Recife: Fundação Joaquim Nabuco/Massangana, 2010.

PINTO, Alexina de Magalhães. Contribuição ao folk-lore brasileiro para a biblioteca infantil. Rio de Janeiro: G. Ribeiro dos Santos, I907.

RAFFAINI, Patricia Tavares. Esculpindo a cultura na forma Brasil: o Departamento de Cultura de São Paulo (I935-I938). São Paulo: Humanitas, 200I.

SANDRONI, Carlos. Mário contra Macunaíma: cultura e política em Mário de Andrade. São Paulo: Vértice, I998.

SANT’ANNA, Denise Bernuzzi de. Cidade das águas: usos dos rios, córregos, bicas e chafarizes em São Paulo (I822-I9OI). São Paulo: Senac, 2007.

SEVCENKO, Nicolau. Orfeu extático na metrópole: São Paulo, sociedade e cultura nos frementes anos 20. São Paulo: Companhia das Letras, I992.

SILVA, Carolina da Costa e. O álbum Parques Infantis como objeto cultural: São Paulo, I937. 200 f. Dissertação (Mestrado em Educação). Faculdade de Educação, Universidade de São Paulo, 2008.

SILVA, Giovanna Camila. A partir da inspetoria de educação física de Minas Gerais (I927-I937): movimentos para a escolarização da educação física no estado. 228 f. Dissertação (Mestrado). Faculdade de Educação, Universidade Federal de Minas Gerais, Belo Horizonte, 2009.

SOARES, Carmen Lucia. O pensamento médico higienista e a educação física no Brasil: 1850-I930. Dissertação (Mestrado em Educação). Programa de Pós-Graduação em História e Filosofia da Educação, Pontifícia Universidade Católica, São Paulo, I990.

. Três notas sobre a natureza, educação do corpo e ordem urbana (I900-I940). In: Uma educação pela natureza: a vida ao ar livre, o corpo e a ordem urbana. São Paulo: Autores Associados, 20I6, p. 9-45.

SOARES, Carmen Lucia; SANTOS NETO, Samuel Ribeiro dos. À sombra das árvores... respirando ar puro: educação e divertimentos junto à natureza na São Paulo dos anos I920. Educ. rev., Belo Horizonte, v. 34, 20I8. Disponível em <http://www.scielo.br/scielo.php?script=sci_arttext\&pid=SoI02-469820I8000I0oI78\&lng=pt\&nrm=iso >. Acesso em: 27 out. 20I8. http://dx.doi. org/IO.I590/OI02-4698I93539.

WIGGERS, Ingrid Dittrich; OLIVEIRA, Mariana da Silva de; FERREIRA, Ivan Vilela. Infância e educação do corpo: as mídias diante das brincadeiras tradicionais. Em Aberto, Brasília, v. 3I, n. Io2, maio-ago. 20I8, p. I77-I90.

YUASA, Yûichi. Kurepasu jishû gachô. Tokyo: Shunk-Shunkô-dô, I933, v. I, 3, 5, 6. 